\title{
Lysozyme Turnover in the Rat
}

\author{
Niels Ebbe Hansen, Hans Karle, and Vagn Andersen \\ From the Division of Hematology, Department of Medicine A, Rigshospitalet, \\ University Hospital of Copenhagen, Copenhagen, Denmark
}

A B S T R A C T Lysozyme turnover in the rat was studied with ${ }^{125} \mathrm{I}$-labeled rat lysozyme. It was found that plasma lysozyme has a rapid disappearance rate with a half-life of $75 \mathrm{~min}$. The rate of synthesis was calculated at $3.4 \mu \mathrm{g} / \mathrm{min}$ per $100 \mathrm{~g}$ rat. This rate of synthesis was compared with figures from the literature for the turnover rate of neutrophilic granulocytes, and the data were consistent with the concept that disintegrating neutrophils are the main source of plasma lysozyme.

The distribution of enzymatic lysozyme activity and of radioactive lysozyme was studied in several organs. Very high enzymatic activity was found in leukocytes as were considerable activities in lungs, kidneys, bone marrow, spleen, and intestine; little enzymatic activity was found in the urine. High radioactive levels as compared with plasma radioactivity were demonstrated only in the kidneys. This indicates that of the organs studied, the kidney is the predominant site of storage and destruction of plasma lysozyme.

Lysozyme was found to disappear only slowly from the kidneys over a period of 4 days. The data obtained seem to indicate that lysozyme or a lysozyme degradation product precipitable by trichloroacetic acid was released in small amounts from the kidneys to plasma throughout this period.

\section{INTRODUCTION}

Increasing interest in lysozyme (muramidase) as a diagnostic tool in hematology and nephrology has stressed the importance of knowledge of the metabolism of this enzyme. However, few turnover studies of lysozyme have been carried out, and these were performed either with xenogeneic lysozyme (from hen egg white) or with unphysiological amounts of endogenous lysozyme (1-3). The aim of the present study was to investigate lysozyme turnover in the rat using radioactively labeled rat lysozyme.

Received for publication 30 November 1970 and in revised form 20 January 1971.

\section{METHODS}

Animals. Female Wistar rats were used. In the plasma turnover studies the rats weighed $200-280 \mathrm{~g}$; in the other experiments the rats weighed 165-245 g.

Enzymatic activity. Purified rat lysozyme was kindly provided by Professor E. F. Osserman, Columbia University, New York. This lysozyme was isolated from the urine of rats bearing the Shay mononuclear (monocytic?) leukemia; it has been shown to be identical with normal rat lysozyme.

Lysozyme activity was measured by the lysoplate method of Osserman and Lawlor (4) with rat lysozyme as reference standard. Measurements were carried out in duplicate. A good quantitative relationship was found on the lysoplates between lysozyme concentration and zone of clearing.

Labeling procedure. The rat lysozyme was labeled with ${ }^{125}$ I by a chloramine- $T$ method (5); the labeling was performed at New England Nuclear Corp., Boston, Mass. The specific activity of the labeled protein was approximately $0.1 \mathrm{mCi} / \mathrm{mg}$. After iodination the lytic capacity of the enzyme was identical with that of unlabeled protein (as measured by the lysoplate method), and the labeled protein moved electrophoretically as undenatured lysozyme (4). Although the chloramine- $T$ method for labeling proteins, as described by Greenwood, Hunter, and Glover (6), causes considerable denaturation of proteins, the present modification, which uses only $1 / 1000$ of the amount of chloramine-T applied by Greenwood et al., has been shown by in vivo tests not to denature proteins (5).

Experimental procedure. In the plasma turnover studies nine rats were anesthetized with $1 \mathrm{ml}$ of a $2.5 \%$ pentobarbital solution injected intraperitoneally. Catheters were inserted in a jugular vein and a carotid artery. Labeled lysozyme was injected into the vein, the average amount of lysozyme being $65 \mu \mathrm{g}$ dissolved in $250-300 \mu \mathrm{l}$ of a phosphate buffer ( $\mathrm{pH} 6.2)$. Samples of blood $(0.2 \mathrm{ml})$ were drawn from the carotid artery at intervals during $180 \mathrm{~min}$ as indicated in Fig. 1. In order to maintain a normal intravascular volume and blood pressure, isotonic saline equal to the amount of blood removed, was injected after each blood sampling. The rats were killed after $180 \mathrm{~min}$ by injection of air into the carotid artery.

Steady state of the rats was estimated by measuring plasma lysozyme before and after the $180 \mathrm{~min}$ of study. No significant change in activity was seen (mean before and after : 11.8 and $13.1 \mu \mathrm{g} / \mathrm{ml} ; t=2.15 ; P>0.05)$. Production of urine, during the time of study, was approximately $1 \mathrm{ml}$ in all the rats, which was considered an adequate flow of urine.

\footnotetext{
${ }^{1}$ Osserman, E. F. Unpublished observations.
} 


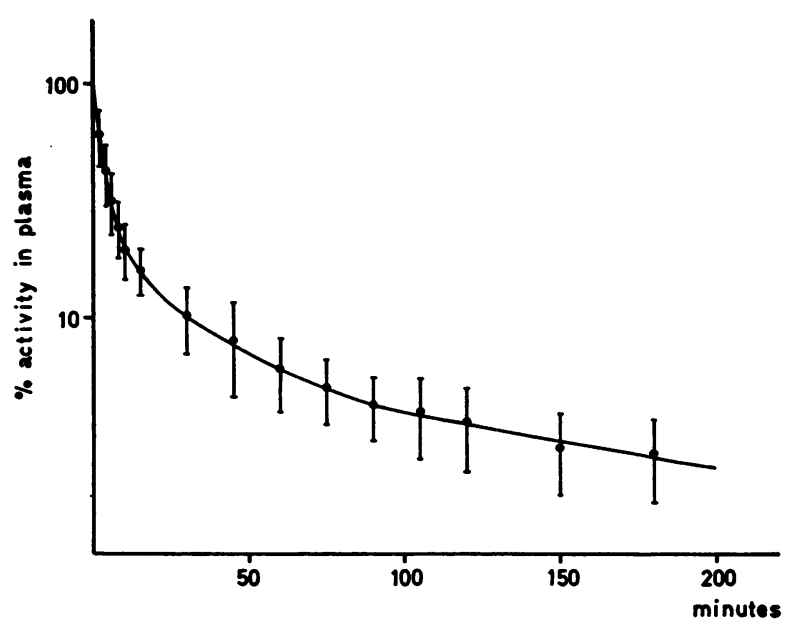

Figure 1 Plasma disappearance curve for injected radioactive lysozyme. The points represent mean values from nine rats; the vertical bars the standard deviation.

In four of the rats (numbers 6-9) plasma volume was measured by ${ }^{131}$ I-labeled human albumin injected together with the ${ }^{125} \mathrm{I}$-labeled lysozyme. The mean plasma volume of these rats was $4.28 \%$ of the body weight $(S D=0.62 \%)$; this figure was used in the calculation of the kinetic data in rats 1-5. A comparison of the kinetic data in rats 1-5 with those of rats 6-9 indicated that human albumin apparently did not influence lysozyme turnover.

Studies on lysozyme turnover over a 4 day period were performed on rats into which labeled lysozyme was injected intraperitoneally. The rats were sacrificed at the intervals indicated in Fig. 2. At each time interval two rats were killed (after pentobarbital anesthesia).

The organs to be studied (lungs, kidneys, spleen, intestines, and liver) were taken out immediately, placed in a phosphate buffer ( $\mathrm{pH}$ 6.2) in the cold, then homogenized in a Potter-Elvehjem homogenizer (20 strokes), and finally centrifuged at $3000 \mathrm{~g}$ for $10 \mathrm{~min}$. Determination of activity in leukocytes and bone marrow was performed on six rats into which labeled lysozyme was injected intraperitoneally. Bone marrow was removed from the femora which were split longitudinally. Leukocytes were isolated by dextran sedimentation of blood obtained by cardiac puncture, followed by hypotonic lysis of the remaining erythrocytes; leukocytes were washed twice in isotonic saline. Leukocytes and bone marrow were homogenized for $5 \mathrm{~min}$ with a glass pestle.

The blood samples and $0.2 \mathrm{ml}$ of the tissue homogenate supernatants were mixed with $1 \mathrm{ml}$ of a $3 \%$ solution of human albumin used as carrier, and protein was precipitated twice with $6 \mathrm{ml}$ of a $10 \%$ solution of trichloroacetic acid. Radioactive counting was performed on the precipitate. Radioactivity was counted in a Gamma spectrometer (Packard Instrument Co., Inc., Downers Grove, Ill.); counting error was $3 \%$ in the weakest samples, usually below $1 \%$.

Method of calculation. Protein-bound plasma radioactivity was plotted against time on semilogarithmic paper. The injected dose divided by plasma volume obtained as described above, was taken as $100 \%$. In all of the rats a slope, as shown in Fig. 1, was obtained. Kinetic data were calculated as indicated by Nosslin, using the "peel-off" tech- nique (7): the plasma disappearance curve (Fig. 1) for each rat was divided in a series of exponential functions, each expressed by intercept $\left(c_{1}\right)$ and slope $\left(b_{1}\right)$. From this the area under the curve (A) was calculated by integration $(A)=\Sigma_{1-n}\left(c_{1} / b_{1}\right)$. Fractional catabolic rate $(\mathrm{FCR})$ was calculated as 1/A. Rate of synthesis was calculated as plasma volume $\times$ plasma lysozyme concentration $\times \mathrm{FCR}$, and expressed as rate of synthesis per $100 \mathrm{~g}$ rat. "Biological half-life" was calculated as B/A $\times 0.693$. (B) $=\Sigma_{1-n}\left(c_{1} / b_{1}{ }^{2}\right)$. The volume of distribution was calculated as $B / A^{2} \times P V$ ( $\mathrm{PV}=$ plasma volume in per cent of body weight).

Lysozyme activity in the organs was expressed as lysozyme enzymatic activity per gram tissue divided by lysozyme enzymatic activity per milliliter plasma and as counts per minute per gram tissue divided by counts per minute per milliliter plasma.

\section{RESULTS}

Table I shows the concentration of lysozyme in various organs of the rat. Fig. 1 shows the composite plasma disappearance curve from the nine rats studied. Table II shows the data calculated from the individual plasma disappearance curves. Table III shows the enzymatic activity and radioactivity in the organs studied as a function of the corresponding plasma values. It is seen that extremely high ratios for enzymatic activity were found in leukocytes and high ratios in lungs, kidneys, bone marrow, spleen, and intestines. Only the kidneys

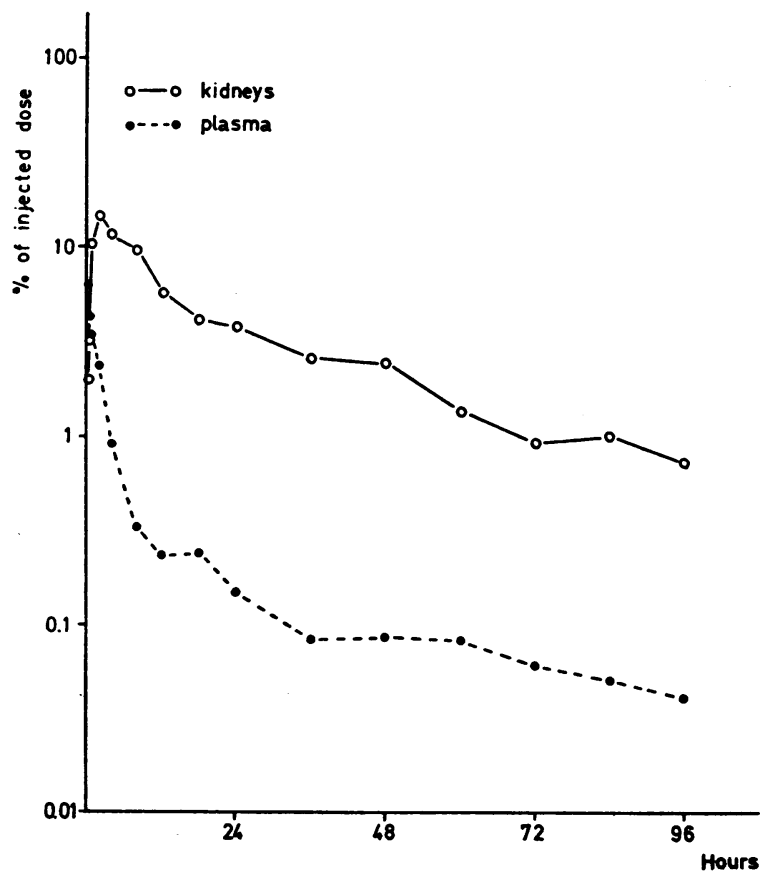

FIGURE 2 Protein-bound radioactivity in kidneys and plasma from rats followed over a 4 day period. Lysozyme was injected intraperitoneally. Activities are expressed as total counts per minute for both kidneys and for total plasma as per cent of injected dose. Each point represents values from two rats. 
TABLE I

Lysozyme Concentrations in Various Organs (Microgram of Lysozyme per Gram of Tissue, Microgram per Milliliter of Plasma and Urine)

\begin{tabular}{lccccccccc}
\hline & & & & & & Bone & & \\
& Plasma & Urine & Leukocytes* & Lung & Kidney & marrow & Spleen & Intestine & Liver \\
\hline Mean & 12.2 & 1.5 & 56,500 & 574 & 563 & 425 & 158 & 78 & 14 \\
SD & 2.6 & 1.1 & 33,966 & 100 & 185 & 169 & 38 & 75 & 5 \\
\hline
\end{tabular}

Figures are based on the results in six rats, except the plasma value, which is based on nine rats.

* The figure is calculated from the finding of $25.4 \pm 15.3 \mu \mathrm{g}$ lysozyme per 1,000,000 lysozyme-containing cells (neutrophilic granulocytes + monocytes) assuming a mean cell volume of $450 \boldsymbol{\mu}^{3}$.

showed a markedly high ratio for protein bound radioactivity; ratios well below unity were found for leukocytes, bone marrow, and intestines, and somewhat higher, but still low values for lungs, spleen, and liver.

Fig. 2 shows protein-bound radioactivity as per cent of injected dose in both kidneys and the total plasma volume from rats followed for up to 4 days (intraperitoneal injection). It is seen that the kidney activity rose steeply concomitantly with a decrease in plasma activity and then decreased slowly during the 4 days of study. Surprisingly, some activity was found in plasma throughout the observation period amounting to approximately $1 / 30$ of the activity found in the kidneys and decreasing at the same rate.

\section{DISCUSSION}

This study has shown that lysozyme disappears rapidly from the blood with a biological half-life of less than 2 $\mathrm{hr}$. The rate of synthesis was found at $3.4 \mu \mathrm{g} / \mathrm{min}$ per $100 \mathrm{~g}$ rat.

Earlier studies concerned with lysozyme turnover have been carried out with large amounts of hen egg white lysozyme or after artificially elevated levels of endogenous lysozyme. These studies are thus connected with two possible errors: the injected lysozyme is foreign to the animal and may not be treated as endogenous lysozyme, or the animals have been studied at unphysiological levels of lysozyme in a nonsteady state. Both factors, as well as differences in the setup of the studies and in the interpretation of the data may explain discrepancies between earlier studies and ours. Thus, in a study by Perri, Faulk, Shapiro, and Money (1) a plasma half-life of $10 \mathrm{~min}$ and a volume of distribution of $7 \%$ of the body weight were found in the rat. In that study, large amounts of hen egg white lysozyme were used, and calculations of the data were carried out on the first steep part of the plasma disappearance curve, which was followed for only $1 \mathrm{hr}$. A somewhat better agreement exists between the study of Balazs and Roepke (2) and ours. Using hen egg white in large amounts, they calculated a volume of distribution of $15 \%$ of the body weight in the rat as compared with
$26 \%$ obtained in this study. Using that figure and the increment of plasma lysozyme after nephrectomy, Balazs and Roepke calculated the production of lysozyme at $330 \mu \mathrm{g} / \mathrm{hr}$ in a $400 \mathrm{~g}$ rat; this would correspond to the production of $1.4 \mu \mathrm{g}$ of lysozyme per min per $100 \mathrm{~g}$ rat, thus reaching a figure somewhat lower than the one obtained in the present study. The difference is probably due to the lower volume of distribution found by Balazs and Roepke.

It has been claimed (8-10) that plasma lysozyme largely stems from the disintegration of lysozyme-containing cells of the blood, i.e. neutrophilic granulocytes and monocytes, the neutrophils being the most important source because of their faster turnover rate (11). Hence, the rate of synthesis calculated in the present study would refer to the rate of lysozyme release from disintegrating neutrophils. Based on the figures for rate of synthesis and for lysozyme content of the leukocytes obtained in this study (Tables I and II) $193 \times 10^{7}$ cells per $\mathrm{kg}$ per day would be degraded. This figure is rather close to the figures obtained in hu-

TABLE II

Plasma Lysozyme Turnover Data

\begin{tabular}{|c|c|c|c|c|}
\hline Rat & $\begin{array}{l}\text { Fractional } \\
\text { catabolic } \\
\text { rate } \\
\text { per minute }\end{array}$ & $\begin{array}{l}\text { Biological } \\
\text { half-life }\end{array}$ & $\begin{array}{l}\text { Volume of } \\
\text { distribution }\end{array}$ & $\begin{array}{c}\text { Rate of } \\
\text { synthesis }\end{array}$ \\
\hline & & $\min$ & $\begin{array}{c}\% \text { of body } \\
\text { weight }\end{array}$ & $\begin{array}{c}\mu g / \min \text { per } \\
100 g \text { body } \\
\text { weight }\end{array}$ \\
\hline 1 & 0.067 & 56 & 23 & 4.3 \\
\hline 2 & 0.043 & 57 & 15 & 2.0 \\
\hline 3 & 0.037 & 103 & 24 & 1.8 \\
\hline 4 & 0.056 & 52 & 18 & 2.6 \\
\hline 5 & 0.054 & 79 & 27 & 2.2 \\
\hline 6 & 0.055 & 108 & 36 & 2.3 \\
\hline 7 & 0.046 & 111 & 38 & 3.1 \\
\hline 8 & 0.091 & 54 & 24 & 5.2 \\
\hline 9 & 0.088 & 50 & 27 & 4.9 \\
\hline Mean & 0.060 & 75 & 26 & 3.4 \\
\hline SD & 0.0189 & 26 & 8 & 1.3 \\
\hline
\end{tabular}

Lysozyme Turnover in the Rat 
TABLE III

Relation Between (A) Enzymatic and (B) Radioactive Lysozyme in Organs and in Plasma

\begin{tabular}{lccccccc}
\hline & Leukocytes & Lung & Kidney & Bone marrow & Spleen & Intestine & Liver \\
\hline $\begin{array}{c}\text { A. Enzymatic } \\
\quad \begin{array}{l}\text { lysozyme } \\
\text { activity }\end{array}\end{array}$ & $2819 \pm 2198$ & $44 \pm 14$ & $41 \pm 12$ & $24 \pm 12$ & $11 \pm 2$ & $9 \pm 7$ & $1 \pm 0.6$ \\
$\begin{array}{c}\text { B. Radioactive } \\
\text { lysozyme }\end{array}$ & 0 & $1.0 \pm 0.3$ & $67.1 \pm 17.5$ & $0.2 \pm 0.17$ & $2.5 \pm 0.6$ & $0.4 \pm 0.3$ & $0.9 \pm 0.6$ \\
& & $(0.3 \pm 0.1)^{*}$ & $(0.1 \pm 0.03)$ & & $(0.1 \pm 0.05)$ & $(0.02 \pm 0.006)$ & $(0.07 \pm 0.04)$
\end{tabular}

Figures expressed as (A) microgram lysozyme per gram tissue divided by microgram lysozyme per milliliter plasma, and (B) counts per minute per gram tissue divided by counts per minute per milliliter plasma. Based on observations in six rats; figures given are mean \pm SD.

* Figures in parentheses indicate corresponding values for albumin-131I.

mans with $\mathrm{DF}^{22} \mathrm{P}$ (di-isopropyl fluorophosphate with radioactive phosphorus)-labeled leukocytes $\left(163 \times 10^{7}\right.$ cells per $\mathrm{kg}$ per day, with $95 \%$ limits at $50-340 \times 10^{7}$ ) (12). These figures from humans would expectedly be similar in the rat, since a leukocyte disappearance half-life of 6.0-7.6 hr have been found in that animal (13) (as compared with $4-10 \mathrm{hr}$ in humans), and since the neutrophil count in the rat is similar to the one found in humans (14). It should be noted, however, that this calculation is based on the assumption that the extraction of lysozyme from neutrophils, when determining lysozyme content per cell, is complete.

The concentration of lysozyme in the plasma and the organs shown in Table I corresponds rather closely to the findings of others $(1,2)$, although earlier studies have used a turbidometric method for the estimation of lysozyme and hen egg white as a reference standard. The leukocytes contain large amounts of lysozyme; considerable concentrations were found in the lungs, kidneys, bone marrow, spleen, and intestines. Only small amounts were found in the urine.

A high concentration of lysozyme in an organ may mean that this organ $(a)$ contains cells capable of synthesizing lysozyme, $(b)$ is a site of storage or destruction of lysozyme-containing cells, and/or $(c)$ takes up lysozyme from the plasma. Injected lysozyme will be assumed to accumulate only in organs of group (c) (provided that catabolism is not instantaneous). Of the organs studied, only the kidneys with their radioactive tissue-plasma ratio of 67 take up considerable amounts of plasma lysozyme, and this points to the kidneys as the main organ of degradation of lysozyme liberated from cells.

Since this calculation offers a rough estimate only, it is difficult to evaluate radioactive tissue-plasma lysozyme ratios around unity found in the spleen, lungs, and liver. The radioactivity of these organs is higher than would be expected on the basis of their contents of extracellular fluid and would thus indicate that storage or degradation of plasma lysozyme takes place to some extent in these organs; this would especially apply to the spleen with its ratio of 2.5. This accumulation of radioactivity in the spleen could be explained by partial denaturation of lysozyme during the labeling procedure. This possibility cannot be entirely refuted even if the lytic capacity and the electrophoretic mobility were identical with those of undenatured lysozyme. However, denaturation would be expected to lead to a similar or even greater accumulation in the liver (15) and this was not found to be the case.

The neutrophilic leukocytes did not take up any labeled lysozyme; since the protein synthesis of these cells is very limited (16), this indicated that lysozyme is incorporated in these cells before they leave the bone marrow. The low uptake of radioactive lysozyme in the bone marrow seems to indicate that this enzyme is synthesized de novo by the bone marrow cells.

The high enzymatic activity of the bone marrow reflects the high concentration of neutrophils, monocytes, and their precursors. In addition, it may also indicate that the bone marrow is a site of degradation of lysozyme-containing cells. This would fit well with the finding of Keeler (17) who demonstrated a high lysozyme arteriovenous difference in rat bone marrow, and would also be in agreement with the demonstration that lysozyme activity in bone marrow plasma of humans exceeds the activity of peripheral blood plasma by a factor 3 (18).

Lysozyme is believed to be filtered in the glomeruli, and reabsorbed and possibly degraded in the proximal tubules. Thus, nephrectomy leads to a rise in plasma lysozyme (2), lysozyme has been demonstrated by immunofluorescence in the proximal tubules (19), and damage to the proximal tubules leads to lysozymuria (2). The fate of lysozyme in the proximal tubules is not known; it is most likely, however, that lysozyme is degraded here. Thus, Maack has shown that mouse kidney slices catabolize lysozyme (3), although others have not been able to confirm this (17). 
The present study clearly demonstrates the important role of the kidney in removing lysozyme from the blood. Thus, protein-bound radioactivity was found in very high concentration in kidney tissue, and it was shown that kidney radioactivity rises steeply concomitantly with a decrease in plasma radioactivity. Radioactivity precipitable by trichloroacetic acid is kept for a long time in the kidney since activity was demonstrated 4 days after the injection, a finding similar to that of Maack in the mouse (3). A comparison of the amount of protein-bound radioactivity disappearing from the kidneys (calculated from the pool of lysozyme in both kidneys and the slope shown in Fig. 2) with the amount disappearing from plasma during the first $8 \mathrm{hr}$ after injection indicated a close proximity of these values.

Surprisingly, it was found that some plasma radioactivity could be demonstrated throughout the 4 days study period. The significance of this finding is unknown. A possible explanation is the continuous release of small amounts of lysozyme or a lysozyme product still precipitable with trichloroacetic acid from the kidneys to the plasma.

\section{ACKNOWLEDGMENTS}

We express our sincere thanks to Professor E. F. Osserman, Columbia University, New York, for kindly leaving purified rat lysozyme at our disposal.

This work was supported by grants from the Danish Medical Research Council and from the Medical Research Foundation for Copenhagen, the Faroe Islands, and Greenland.

\section{REFERENCES}

1. Perri, G. C., M. Faulk, E. Shapiro, and W. L. Money. 1964. Role of the kidney in accumulation of egg white muramidase in experimental animals. Proc. Soc. Exp. Biol. Med. 115: 189.

2. Balazs, T., and R. R. Roepke. 1966. Lysozymuria induced in rats by nephrotoxic agents. Proc. Soc. Exp. Biol. Med. 123: 380.

3. Maack, T. 1967. Changes in the activity of acid hydrolases during renal reabsorption of lysozyme. J. Cell Biol. 35 : 268.
4. Osserman, E. F., and D. P. Lawlor. 1966. Serum and urinary lysozyme (muramidase) in monocytic and monomyelocytic leukemia. J. Exp. Med. 124: 921.

5. McConahey, P. J., and F. J. Dixon. 1966. A method of trace iodination of proteins for immunologic studies. Int. Arch. Allergy Appl. Immunol. 29: 185.

6. Greenwood, F. C., W. M. Hunter, and J. S. Glover. 1963. The preparation of ${ }^{131} \mathrm{I}$-labelled human growth hormone of high specific radioactivity. Biochem. J. 89: 114.

7. Nosslin, B. 1966. Applications of tracer theory to protein turnover studies. J. Nucl. Biol. Med. 9: 2.

8. Fink, M. E., and S. C. Finch. 1966. Serum muramidase and granulocyte turnover. Clin. Res. 14: 316.

9. Fink, M. E., and S. C. Finch. 1968. Serum muramidase and granulocyte turnover. Proc. Soc. Exp. Biol. Med. $127: 365$.

10. Jollés, P., M. Sternberg, and G. Mathé. 1965. The relationship between serum lysozyme levels and the blood leukocytes. Israel J. Med. Sci. 1: 445.

11. van Furth, R. 1970. Origin and kinetics of monocytes and macrophages. Seminars Hematol. 7: 125.

12. Cartwright, G. E., J. W. Athens, and M. M. Wintrobe. 1964. The kinetics of granulopoiesis in normal man. Blood. 24 : 780.

13. Gerecke, D., B. Schultze, and W. Maurer. 1970. Autoradiographische Bestimmung der mittleren Verweilzeit neutrophiler Granulozyten im Blut der Ratte mittels Dauerinfusion von ${ }^{3} \mathrm{H}$-Thymidin. Experientia (Basel). 26: 311 .

14. Spector, W. S., editor. 1956. Handbook of Biological Data. W. B. Saunders Company, Philadelphia.

15. Dewey, W. C., and J. D. Hunter. 1960. Inhomogeneity of iodinated human serum albumin as detected with rat liver. J. Appl. Physiol. 15: 961.

16. Stjernholm, R. S. 1968. The metabolism of human leukocytes. Plenary session papers. Proc. Int. Congr. Soc. Hematol. 175.

17. Keeler, R. 1970. The effect of bilateral nephrectomy on the production and distribution of muramidase (lysozyme) in the rat. Can. J. Physiol. Pharmacol. 48: 131.

18. Hansen, N. E., H. Karle, and V. Andersen. 1969. Muramidase activity of bone marrow plasma. Studies in haematologically normal individuals and in granulocytopenic patients. Acta Med. Scand. 185: 387.

19. Glynn, A. A. 1968. Lysozyme: antigen, enzyme and antibacterial agent. Sci. Basis Med. Annu. Rev. 31. 